\title{
EFFICIENT PORTFOLIOS \\ IN THE ASSET LIABILITY CONTEXT
}

\author{
By Alex Keel and Heinz H. Müller \\ University of St. Gallen
}

\begin{abstract}
The set of efficient portfolios in an asset liability model is discussed in detail. The occurence of liabilities leads to a parallel shift of the efficient set. Under an appropriate assumption, the shift vector can be decomposed in different components. For the special case, where the investor is a pension fund, it is shown how shortfall constraints can be reconciled with efficiency. Finally, optimality conditions for the market portfolio are derived.
\end{abstract}

\section{KEYWORDS}

Portfolio Theory, Asset Liability Management, Mean Variance Analysis, Shortfall Constraint.

\section{INTRODUCTION}

Modern Portfolio Theory started with Markowitz' (1952) famous article. The Markowitz approach leads to a set of efficient portfolios which can be represented as combinations of two reference portfolios ("two fund separation"). Due to this property SHARPE (1964) and LINTNER (1965) derived their Capital Asset Pricing Model (CAPM).

Recently, with growing importance of pension finance more and more attention is paid to portfolio models taking into account liabilities (see e.g. SHARPE/TINT (1990), ELTON/GRUBER (1992), JÄGER/ZIMMERMANN (1992), LEIBOWITZ/KOGELMAN/BADER (1992)). WILKIE (1985) and WISE (1984a,b, 1987a,b, 1989) analyse portfolios in a more general context. Their efficiency criterion is formulated with respect to the cost of funding and the first two moments of final surplus.

The literature on continuous time finance allows for state dependent preferences and investment opportunities (see e.g. MerTon (1992), Chapter 15). As a special case this very general model covers liabilities and one can apply the mutual fund theorems derived by MERTON (1973).

In our article we use the model proposed by SHARPE/TINT (1990) which puts the asset liability problem in a very close relationship to traditional mean variance portfolio theory. According to SHARPE/TINT most practitioners still favour the traditional Markowitz approach and are reluctant to take fully into account liabili- 
ties. Therefore, a model with a strong link to standard theory is useful for the analysis of liabilities. As a main result we show that efficient portfolios can be decomposed into a minimum risk component, liability components and a return generating component. In contrast to continuous time models (see e. g. ADLER/DuMAS (1983)) the liability components do not depend on the preferences of the investor.

Our article is structured as follows:

The standard optimization problem for an investor with liabilities is formulated and discussed in section 2 . The model deals with the investment problem of a pension fund, but can be easily applied in a much broader context. In section 3 results on the set of efficient portfolios are derived. It is shown that liabilities lead to a parallel shift of the efficient set. The additional assumption that the growth rate of the liability depends linearly on several factors (e.g. bond return, inflation rate, rate of economic growth, etc.) allows for a further decomposition of the liability component. Section 4 deals with shortfall constraints for pension funds. In this case the pension fund will also choose a portfolio belonging to the efficient set provided the shortfall constraint is properly formulated. Finally, in section 5 the optimality conditions for the market portfolio in the asset liability framework are discussed.

\section{PoRTFOlio CHOICE IN THE CASE OF LIABILITIES}

In the case of a pension fund, liabilities are not readily marketable and therefore do not have a market value. The work of WILKIE (1985) and WISE (1984a,b, $1987 \mathrm{a}, \mathrm{b}, 1989$ ) is directed partly towards finding a suitable present value. Here, we assume that some specific accounting rules are used to calculate an initial value $L_{0}$ of the future net obligations. If the same method is applied one period later, a value $\tilde{L}_{1}$ results. Hence, from todays point of view, the growth rate of the liabilities is a random variable, which is given by

$$
\tilde{R}_{L}=\frac{\tilde{L}_{1}-L_{0}}{L_{0}}
$$

On the other hand, we assume that assets are valued according to market prices and we denote the initial value of assets by $A_{0}$. There are $n$ risky investment opportunities $i \in I=\{1, \ldots, n\}$, with rate of return $\tilde{R}_{\mathrm{i}}$. The investment strategy of the pension fund is given by the choice of a portfolio

$$
\boldsymbol{x}=\left(x_{i}\right)_{i \in I} \text {, with } \sum_{i \in I} x_{i}=1
$$

1 Typically the growth rate of the liabilities depends on changes of interest rate structure, inflation rate and on real wage changes 
Therefore, the market value of assets after one period is given by

$$
\tilde{A}_{1}=A_{0}\left[1+\tilde{R}_{A}(\boldsymbol{x})\right],
$$

where

$$
\tilde{R}_{A}(\boldsymbol{x})=\sum_{i \in I} x_{i} \tilde{R}_{i}
$$

denotes the rate of return on portfolio $\boldsymbol{x}$.

\section{Surplus Optimization}

Depending on its portfolio choice $\boldsymbol{x}$ a pension fund with initial surplus

$$
S_{0}=A_{0}-L_{0}
$$

attains after one period the surplus

$$
\tilde{S}_{1}=\tilde{A}_{1}-\tilde{L}_{1}=A_{0}\left[1+\tilde{R}_{A}(x)\right]-L_{0}\left[1+\tilde{R}_{L}\right]
$$

The goal is to optimize some functional of the increase in surplus

$$
\tilde{S}_{1}-S_{0}=A_{0} \tilde{R}_{A}(x)-L_{0} \tilde{R}_{L}
$$

that will lead to mean-variance as the relevant criteria.

As in Sharpe/Tint (1990) we use the normalization

$$
\tilde{R}_{S}=\frac{\tilde{S}_{1}-S_{0}}{A_{0}}=\tilde{R}_{A}(\boldsymbol{x})-\frac{1}{f_{0}} \tilde{R}_{L} \text {, with } f_{0}=\frac{A_{0}}{L_{0}}
$$

In our paper we shall refer to $f_{0}$ as the funding ratio of the pension fund.

Now the methodology of Markowitz ${ }^{2}$ leads to the optimization problem

$$
\min _{x} \operatorname{Var}\left[\tilde{R}_{A}(\boldsymbol{x})-\frac{1}{f_{0}} \tilde{R}_{L}\right]
$$

2 For a detailed presentation of the Markowitz methodology see INGERSOLL (1987), Chapter 4 or HUANG/LiTZENBERGER (1988), Chapter 3. 
subject to

(0)

$$
\begin{array}{r}
E\left[\tilde{R}_{A}(\boldsymbol{x})-\frac{1}{f_{0}} \tilde{R}_{L}\right] \geq r_{S} \\
\sum_{i \in I} x_{i}=1,
\end{array}
$$

where the parameter $r_{s}$ has to be chosen in accordance with the risk tolerance of the pension fund ${ }^{3,4,5}$. We use the following terminology:

\section{Definition:}

a) A portfolio $x^{*}$ is called efficient if it solves the optimality problem of $(0)$ for some $r_{s}$.

b) The set $E$ of all efficient portfolios is called efficient set.

The properties of the efficient set will be analysed in section 3 . Now, we shall shortly discuss general applications of the asset liability model. As it is pointed out by SHARPE/TINT (1990) the asset liability model is appropriate not only for very different types of liabilities (foreign currency obligations, debt structure, obligations of an insurance company, etc.) but also in the case where investors own fixed assets (human capital, ownership of a house, etc.). Moreover, for an investor interested in real rather than in nominal returns the asset liability model can be used. The growth rate of the liability $\tilde{R}_{L}$ has to be set equal to the inflation rate (SolnIK (1978)). Of course, the original Markowitz model is a special case of the asset liability model $^{6}$.

3 In the specific literature the normalizations $\frac{\bar{s}_{i}-S_{0}}{L_{0}}$ and $\frac{\bar{S}_{1}-S_{i 1}}{S_{11}}$ for $S_{01}>0$ are also used. However, with the parameter $r_{i}$ adjusted, all types of normalization lead to the same optimal portfolio.

4 WILKIE (1985) and WISE (1984a,b, 1987a,b, 1989) used an efficiency concept with respect to $E\left[\tilde{S}_{1}(x)\right], V a r\left[\tilde{S}_{1}(x)\right]$ and $A_{0}$. Their decision variables are $\boldsymbol{x}$ and $A_{0}$. In this sense optimization takes place with respect to the investment policy $\boldsymbol{x}$ and the cost of funding $A_{0}$. They derive very interesting properties of the resulting efficient set.

Our purpose is to analyse the asset liability problem for a fixed funding ratio $f_{0}$. This limitation avoids complexity, allows for very explicit results and makes our analysis compatible with the standard literature on this topic.

5 Similar models were used by MAYERS (1972) to deal with income from nontraded assets and by SoLN1K (1978) in his article on portfolio choice under inflation. SVENSSON/WERNER (1993) presented a model for nontraded assets in the continuous time framework.

6 This is easily seen by setting the growth rate of the liability $\tilde{R}_{L}$ equal to zero. 


\section{THE EFFICIENT SET AND ITS PROPERTIES}

\subsection{Characterization of Efficient Portfolios}

In this section the structure of the efficient set $E$ is analysed and it is discussed how this set depends on the growth rate of the liability $\tilde{R}_{\mathrm{L}}$. We restrict our analysis to the case where all assets $i \in I$ are risky ${ }^{7}$. The existence of a riskless asset would lead to the same qualitative properties of the efficient set without giving additional insight.

The rate of return of a portfolio $\boldsymbol{x}$ is given by

$$
\tilde{R}_{A}(x):=\sum_{i \in I} x_{i} \tilde{R}_{i}
$$

and, provided that the first and second moments of $\tilde{R}_{L}$ and $\tilde{R}_{\mathrm{i}}, i \in I$ exist, the optimization problem $(0)$ of section 2 can be transformed into ${ }^{8}$

$$
\min _{x \in R^{n}}\left\{\frac{1}{2} \sum_{i, j \in I} x_{i} V_{i j} x_{j}-\frac{1}{f_{0}} \sum_{i \in I} \gamma_{i} x_{i}\right\}
$$

subject to

(A) $\sum_{i \in I} \mu_{i} x_{i} \geq \hat{r}$

$$
\text { (B) } \sum_{i \in I} x_{i}=1
$$

with

$$
\begin{aligned}
V_{i j} & =\operatorname{Cov}\left(\tilde{R}_{i}, \tilde{R}_{j}\right), i, j \in I \\
\gamma_{i} & =\operatorname{Cov}\left(\tilde{R}_{i}, \tilde{R}_{L}\right), \quad i \in I \\
\mu_{i} & =E\left(\tilde{R}_{i}\right) \quad, \quad i \in I
\end{aligned}
$$

For the analysis of $(0.1)$ we assume:

A.1. 1) The covariance matrix $V=\left(V_{i, j}\right)_{i, j \in I}$ to be regular

2) There exist $i, j \in I$ such that $E\left(\tilde{R}_{i}\right) \neq E\left(\tilde{R}_{j}\right)$

7 A model without a riskless asset is useful for strategic asset allocation. Due to changes in interest rates even money markets are risky for this purpose.

8 In a slightly different context SOLNIK (1978) analysed the same optimization problem. Beyond the different interpretation our discussion of the efficient set will also be somewhat different. 
Under assumption (A.1) a unique solution $x^{*}$ of (0.1) always exists. Furthermore, there exists $\hat{r}_{M I N}$ such that constraint (A) holds with equality if and only if $\hat{r} \geq \hat{r}_{M I N^{*}}$ According to the Kuhn/Tucker theorem, the necessary and sufficient optimality conditions are given by

$$
\begin{aligned}
V x^{*}-\frac{1}{f_{0}} \boldsymbol{\gamma}-\lambda \boldsymbol{\mu}-\boldsymbol{v} \boldsymbol{e} & =\mathbf{0}, \quad \lambda \geq 0, v \in \mathbf{R} \\
\boldsymbol{\mu} \boldsymbol{x}^{*} & =\hat{r}, \\
\boldsymbol{e}^{\prime} \boldsymbol{x}^{*} & =1,
\end{aligned}
$$

Notation:

$$
\begin{gathered}
V=\left(V_{i j}\right)_{i, j \in I}, \quad \boldsymbol{\gamma}=\left(\gamma_{i}\right)_{i \in I}, \quad \boldsymbol{\mu}=\left(\mu_{i}\right)_{i \in I}, \\
\boldsymbol{e}^{\prime}=(1,1, \ldots, 1) \in \mathbf{R}^{n} .
\end{gathered}
$$

\section{Minimum Variance Portfolio}

The minimum variance portfolio $x^{M I N}$ is obtained by omitting constraint (A) in (0.1). This leads to $\lambda=0$ and from equation ( 3 ) and (5) one concludes

$$
\boldsymbol{x}^{M I N}=\frac{1}{f_{0}} V^{-1} \gamma+\frac{1}{f_{0}} \cdot \frac{1}{\boldsymbol{e}^{\prime} V^{-1} \boldsymbol{e}}\left[f_{0}-\boldsymbol{e}^{\prime} V^{-1} \boldsymbol{\gamma}\right] V^{-1} \boldsymbol{e}
$$

$$
\boldsymbol{x}^{M I N}=\frac{1}{\boldsymbol{e}^{\prime} V^{-1} \boldsymbol{e}} V^{-1} \boldsymbol{e}+\frac{1}{f_{0}}\left[V^{-1} \boldsymbol{\gamma}-\frac{\boldsymbol{e}^{\prime} V \boldsymbol{\gamma}}{\boldsymbol{e}^{\prime} V^{-1} \boldsymbol{e}} V^{-1} \boldsymbol{e}\right]
$$

The first term in (7)

$$
\hat{\boldsymbol{x}}^{M I N}=\frac{1}{\boldsymbol{e}^{\prime} V^{-1} \boldsymbol{e}} V^{-1} \boldsymbol{e}
$$

corresponds to the minimum variance portfolio in the absence of liabilities.

The second term in (7)

$$
z^{M I N}=\frac{1}{f_{0}}\left[V^{-1} \boldsymbol{\gamma}-\frac{\boldsymbol{e}^{\prime} V^{-1} \boldsymbol{\gamma}}{\boldsymbol{e}^{\prime} V^{-1} \boldsymbol{e}} \cdot V^{-1} \boldsymbol{e}\right] \quad \text { with } \sum_{i \in I} z_{i}^{M I N}=0
$$

is the correction $\boldsymbol{x}^{M I N}-\hat{\boldsymbol{x}}^{M I N}$ stemming from the liability. It is important to note that $z^{M I N}$ is linear in $\gamma$. 
The decomposition

$$
\boldsymbol{x}^{M I N}=\hat{\boldsymbol{x}}^{M I N}+z^{M I N}
$$

turns out to be useful for the discussion of the efficient set.

\section{Efficient Portfolios}

For $\hat{r}>\hat{r}_{M I N}=\mu^{\prime} x^{M I N}$ one obtains $\lambda>0$ in equation (3) and the general solution is of the form

$$
x^{*}=x^{M I N}+\lambda z^{*}
$$

where

$$
z^{*}=V^{-1} \boldsymbol{\mu}-\frac{\boldsymbol{e}^{\prime} V^{-1} \boldsymbol{\mu}}{\boldsymbol{e}^{\prime} V^{-1} \boldsymbol{e}} V^{-1} \boldsymbol{e}, \quad \sum_{i \in I} z_{i}^{*}=0
$$

Obviously, $z^{*}$ is not related to the liability. From this we conclude that the efficient set $E$ consists of all portfolios

$$
\boldsymbol{x}^{*}=\hat{\boldsymbol{x}}^{M I N}+z^{M I N}+\lambda z^{*} \quad \lambda \geq 0
$$

Geometrically, the occurence of the liabilities leads to a parallel shift of the efficient set by $z^{M I N}$. Figure 1 illustrates this fact for the special case of $\mathbf{n}=3$.

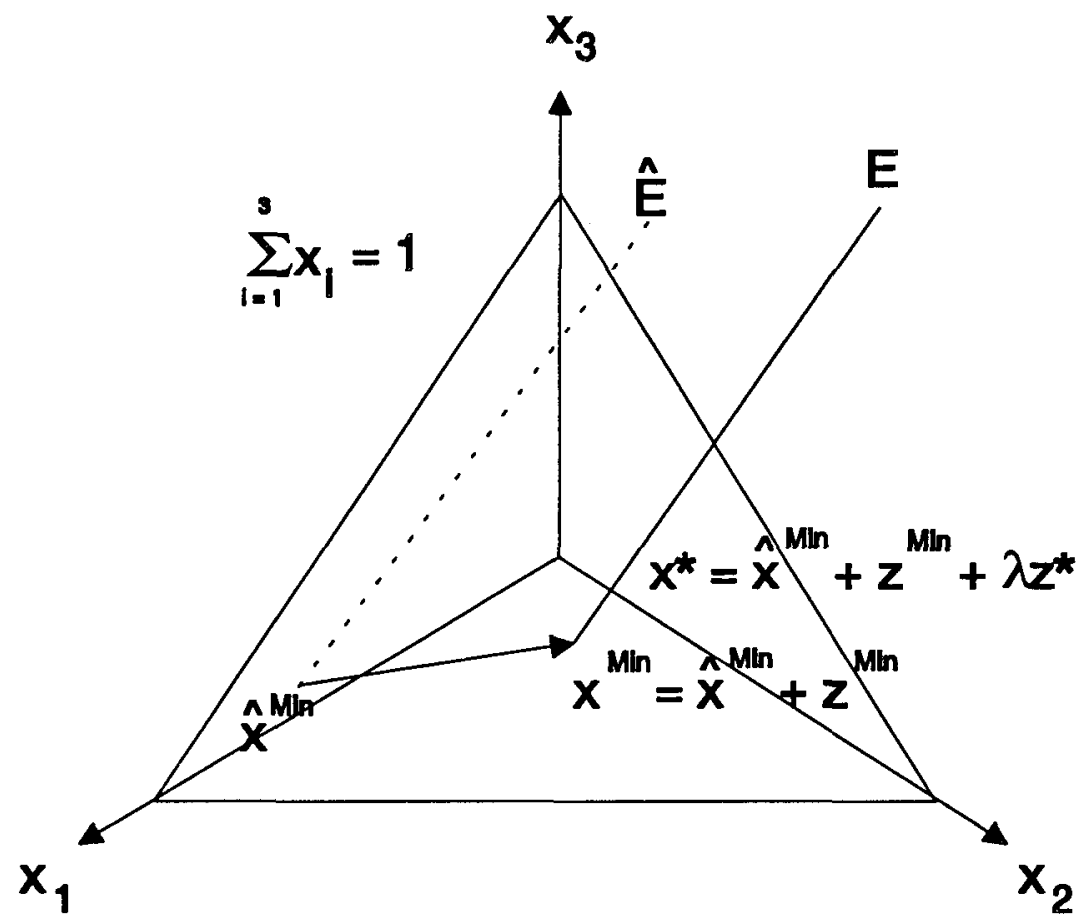


A decomposition of efficient portfolios in the case of liabilities can also be found in WISE (1987a). SVENSSON/WERNER (1993) present a similar decomposition for their model of nontraded assets. However, if in the continuous time framework state variables are used, then the component $z^{M I N}$ will typically depend on preferences ${ }^{9}$.

The results developed in this section crucially depend on the fact that no additional constraints are imposed on the portfolio weights $\boldsymbol{x}_{i}, i \in I$. For a discussion of this topic in the absence of liabilities we refer to MARKowITZ (1987).

\subsection{Efficient Portfolios under an Additional Assumption on Liabilities}

In section 3.1 formula (9) we have seen that the portfolio component $z^{M I N}$ depends linearly on $\left(\gamma_{i}\right)_{i \in I}=\left(\operatorname{Cov}\left(\tilde{R}_{i}, \tilde{R}_{L}\right)\right)_{i \epsilon I}$. In order to take advantage of this linearity we assume

$$
\tilde{R}_{L}=c_{0}+\sum_{h=1}^{k} c_{h} \tilde{R}_{L}^{h}
$$

According to this assumption, $\tilde{R}_{L}$ depends linearly on several factors $\tilde{R}_{L}^{h}, h=1, \ldots, k$, e.g. return on bonds, inflation, economic growth, etc. ${ }^{10}$

An immediate consequence of (A.2) is

$$
\gamma=\sum_{h=1}^{k} c_{h} \gamma^{h} \quad, \quad \text { with } \gamma_{i}^{h}=\operatorname{Cov}\left(\tilde{R}_{L}{ }^{h}, \tilde{R}_{i}\right)
$$

Due to (9) this leads to

$$
z^{M I N}=\frac{1}{f_{0}} \sum_{h=1}^{k} c_{h} z^{h} \quad, \quad \text { with } z^{h}=V^{-1} \gamma^{h}-\frac{e^{\prime} V^{-1} \gamma^{h}}{e^{\prime} V^{-1} e} V^{-1} e
$$

9 This can easily be seen in the following example (see aiso ADLER/Dumas (1983), p. 943). Assume that an investor is only interested in real wealth at a certain point of time $T$. Let $W_{T}$ denote the nominal wealth in $T$ and consider the corresponding price level $P_{T}$ as a state variable. The objective function of the investor is given by the expected utility of real wealth in $T$, i. e. $E\left[\left(\frac{w_{T}}{P_{T}}\right)\right]$. Obviously for $u(x)=e n x$ inflation does not affect the investment strategy whereas for other utility functions this is typically the case.

10 With assumption A.2 the concept of a factor model for the liabilities is introduced. If the returns of the assets can also be explained by a set of factors containing, $\tilde{R}_{L}{ }^{1}, \ldots, \tilde{R}_{L}{ }^{k}$, then the techniques of arbitrage pricing theory (APT) could be applied. Factor models and APT are presented e.g. in JARROw (1988) and INGERSOLL (1987), Chapter 7. 
In other words, each factor $\tilde{R}_{L}^{h}, h=1,2 \ldots, k$ leads to a correction $z^{h}$ and the total correction is a linear combination of $z^{l}, \ldots, z^{k}$. Hence, under (A.2) efficient portfolios are of the form

$$
\boldsymbol{x}^{*}=\hat{\boldsymbol{x}}^{M I N}+\frac{1}{f_{0}} \sum_{h=1}^{k} c_{h} z^{h}+\lambda z^{*} \quad \lambda \geq 0
$$

The case $n=3, k=2, f_{0}=1$ is illustrated by figure 2 .

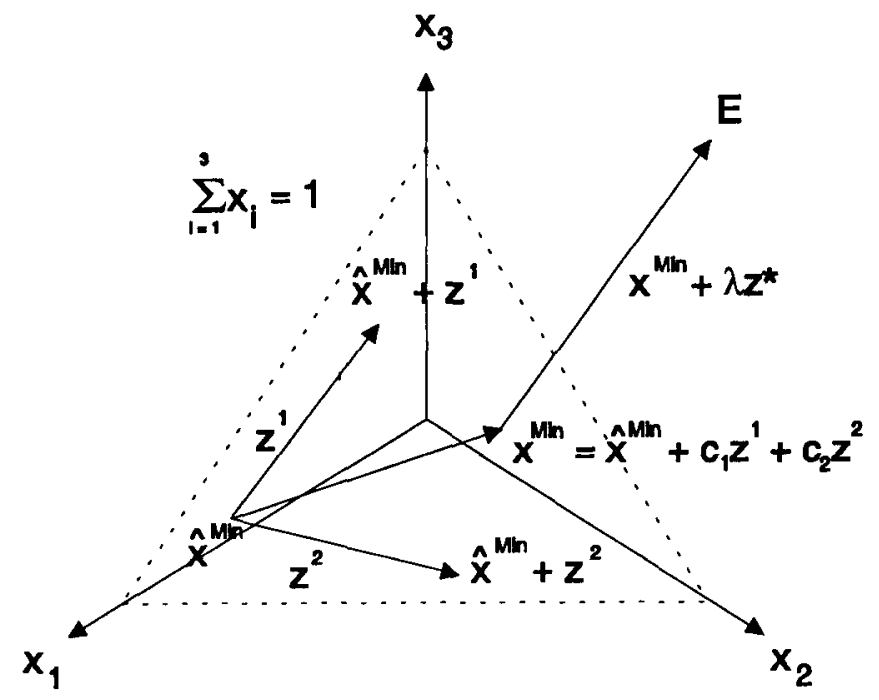

As a practical consequence of formula (15), all factors $\tilde{R}_{L}^{h}$, with $\left\|z^{h}\right\|$ sufficiently small can be neglected for an asset liability analysis.

\subsection{Efficient Frontier}

In this section we analyse the efficient frontier. First, one obtains

$$
\operatorname{Cov}\left[\tilde{R}_{A}\left(z^{*}\right), \tilde{R}_{A}\left(x^{M I N}\right)-\frac{1}{f_{0}} \tilde{R}_{L}\right]=0
$$

This result follows immediately from (7) and the formula

$$
\operatorname{Cov}\left[\tilde{R}_{A}\left(z^{*}\right), \tilde{R}_{A}\left(x^{M I N}\right)-\frac{1}{f_{0}} \tilde{R}_{L}\right]=z^{*_{1}} V x^{M I N}-\frac{1}{f_{0}} z^{*_{1}} \gamma
$$


From (16) and (11) we conclude that all efficient portfolios $x^{*}$ satisfy

$$
\begin{aligned}
& E\left[\tilde{R}_{A}\left(x^{*}\right)-\frac{1}{f_{0}} \tilde{R}_{L}\right]=E\left[\tilde{R}_{A}\left(x^{M I N}\right)-\frac{1}{f_{0}} \tilde{R}_{L}\right]+\lambda E\left[\tilde{R}_{A}\left(z^{*}\right)\right] \\
& \operatorname{Var}\left[\tilde{R}_{A}\left(x^{*}\right)-\frac{1}{f_{0}} \tilde{R}_{L}\right]=\operatorname{Var}\left[\tilde{R}_{A}\left(x^{M I N}\right)-\frac{1}{f_{0}} \tilde{R}_{L}\right]+\lambda^{2} \operatorname{Var}\left[\tilde{R}_{A}\left(z^{*}\right)\right]
\end{aligned}
$$

Hence, under (A.1) there is a hyperbolic relationship between

$$
E\left[\tilde{R}_{A}\left(\boldsymbol{x}^{*}\right)-\frac{1}{f_{0}} \tilde{R}_{L}\right] \text { and } \sigma\left[\tilde{R}_{A}\left(\boldsymbol{x}^{*}\right)-\frac{1}{f_{0}} \tilde{R}_{L}\right]
$$

whenever the liabilities cannot be fully tracked by a portfolio, i.e.

$$
\operatorname{Var}\left[\tilde{R}_{A}\left(x^{M I N}\right)-\frac{1}{f_{0}} \tilde{R}_{L}\right]>0
$$

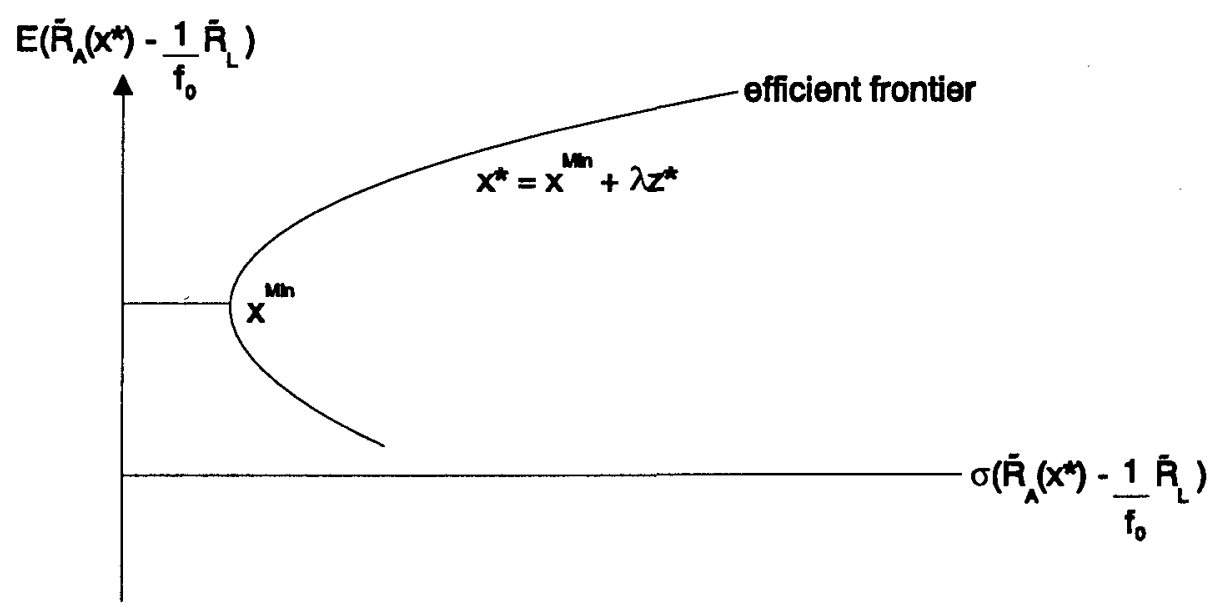


In the case $\operatorname{Var}\left[\tilde{R}_{A}\left(\boldsymbol{x}^{M I N}\right)-\frac{1}{f_{0}} \tilde{R}_{L}\right]=0$ full matching of liabilities is feasible and the hyperbola degenerates to a pair of straight lines. However, this exceptional case occurs if and only if there exists $\left(b_{0}, \ldots, b_{n}\right) \in \mathbf{R}^{n+1}$ such that

$$
\tilde{R}_{L}=b_{0}+\sum_{i=1}^{n} b_{i} \tilde{R}_{i} \quad, \quad \sum_{i=1}^{n} b_{i}=f_{0}
$$

\section{SHORTFALl CONSTRAINTS AND ITS PROPERTIES}

Under a portfolio choice $\boldsymbol{x}=\left(x_{i}\right)_{i \in I}$ after one period the funding ratio is given by

$$
\tilde{f}_{1}(\boldsymbol{x})=f_{0} \frac{1+\tilde{R}_{A}(\boldsymbol{x})}{1+\tilde{R}_{L}}
$$

We shall consider shortfall constraints of the type

$$
\operatorname{Prob}\left\{\tilde{f}_{1}(\boldsymbol{x}) \leq \bar{f}\right\} \leq \delta
$$

Under the assumption

(A.3) The probability distribution of $\left(R_{L}, R_{1}, \ldots, R_{n}\right)$ is multivariate normal the shortfall constraint (19) becomes

$$
1+E\left[\tilde{R}_{A}(x)\right]-\frac{\bar{f}}{f_{0}}\left[1+E\left(\tilde{R}_{L}\right)\right] \geq z_{\delta} \sigma\left[\tilde{R}_{A}(x)-\frac{\bar{f}}{f_{0}} \tilde{R}_{L}\right]
$$

with

$$
\frac{1}{\sqrt{2 \pi}} \int_{z_{\delta}}^{\infty} e^{-\frac{x^{2}}{2}} d x=\delta
$$

Therefore, under (A.1), (A.3) and $\bar{f}=1$ the shortfall constraint (19) has the properties:

1. In the $\left(E\left[\tilde{R}_{A}(x)-\frac{1}{f_{0}} \tilde{R}_{L}\right], \sigma\left[\tilde{R}_{A}(x)-\frac{1}{f_{0}} \tilde{R}_{L}\right]\right)$ space the shortfall constraint is linear. 
2. Assume that some portfolio $x$ satisfies the shortfall constraint. Then, the set $E_{S}$ of all efficient portfolios satisfying the shortfall constraint is nonempty.

Furthermore, there exist $\lambda_{\min }, \lambda_{\max }$ with $0 \leq \lambda_{\min } \leq \lambda_{\max }$, so that

$$
x^{*} \in E_{S} \Leftrightarrow x^{*}=x^{M I N}+\lambda z^{*}, \lambda \in\left[\lambda_{\min }, \lambda_{\max }\right]
$$

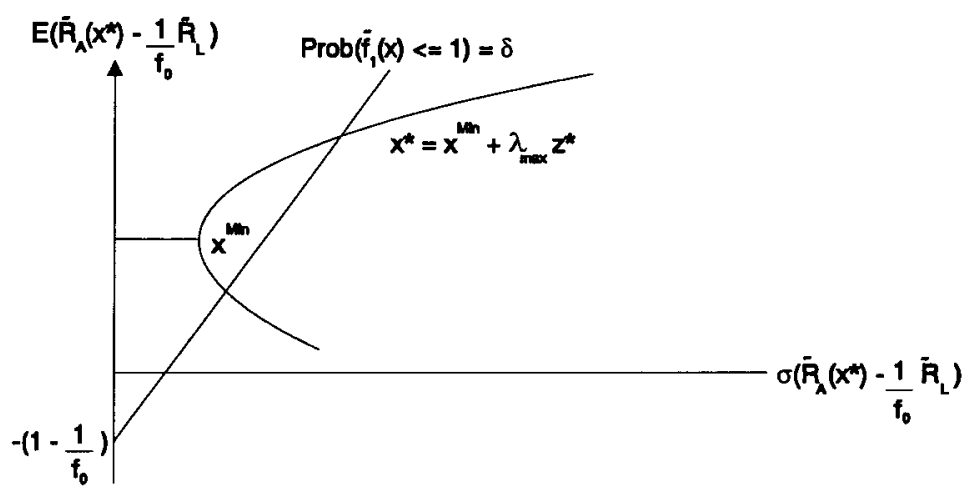

According to these properties shortfall constraints can be reconciled with efficiency by fixing $\bar{f}=1$ and choosing an appropriate value for $\delta$.

\section{OPTIMALITY CONDITIONS AND THE EFFICIENCY \\ OF THE MARKET PORTFOLIO}

In this section we first derive a relationship between asset returns and the return on efficient portfolios. Thereafter, it is argued that for an appropriately defined representative investor the market portfolio is efficient and market equilibrium conditions are obtained.

\subsection{Optimality Result for Efficient Portfolios ${ }^{11}$}

\section{Proposition}

Under (A.1) each efficient portfolio $x^{*}$ with return $\tilde{R}^{*}=\tilde{R}_{A}\left(x^{*}\right)$ satisfies the conditions

$$
E\left(\tilde{R}_{i}\right)-E\left(\tilde{R}_{\beta_{0}}\right)=\frac{\operatorname{Cov}\left(\tilde{R}_{i}, \tilde{R}^{*}-\tilde{R}_{L}\right)}{\operatorname{Cov}\left(\tilde{R}^{*}, \tilde{R}^{*}-\tilde{R}_{L}\right)}\left[E\left(\tilde{R}^{*}\right)-E\left(\tilde{R}_{\beta_{0}}\right)\right] \quad i=1, \ldots, n
$$

11 In this section we assume $f_{0}=1$ 
where

$$
\tilde{R}_{\beta_{0}}=\tilde{R}_{A}\left(x^{0}\right)
$$

is characterized by

$$
\begin{aligned}
\operatorname{Cov}\left[\tilde{R}_{A}\left(x^{0}\right), \tilde{R}^{*}-\tilde{R}_{L}\right] & =0 \\
\sum_{i \in I} x_{i}^{0} & =1
\end{aligned}
$$

\section{Proof:}

For $\boldsymbol{x}^{*}$ the optimality conditions are given by

$$
\begin{gathered}
V \boldsymbol{x}^{*}-\boldsymbol{\gamma}-\lambda \boldsymbol{\mu}-v \boldsymbol{e}=0 \\
\boldsymbol{\mu}^{\prime} \boldsymbol{x}^{*}=E\left(\tilde{R}^{*}\right), \\
\boldsymbol{e}^{\prime} \boldsymbol{x}^{*}=1
\end{gathered}
$$

From (3)-(5) one concludes

$$
\begin{aligned}
& x^{*_{1}} V x^{*}-x^{*} \gamma-\lambda E\left(\tilde{R}^{*}\right)-v=0 \\
& x^{0_{1}} V x^{*}-x^{0_{1}} \gamma-\lambda E\left(\tilde{R}_{\beta_{0}}\right)-v=0
\end{aligned}
$$

The definition of $\boldsymbol{x}^{0}$ and (23) leads to

$$
\lambda E\left(\tilde{R}_{\beta_{0}}\right)+v=0
$$

Now, (3), (22) and (24) imply

$$
\begin{gathered}
V \boldsymbol{x}^{*}-\boldsymbol{\gamma}-\lambda\left[\boldsymbol{\mu}-E\left(\tilde{R}_{\beta_{0}}\right) \boldsymbol{e}\right]=0 \\
\boldsymbol{x}^{*} V \boldsymbol{x}^{*}-\boldsymbol{x}^{*} \boldsymbol{\gamma}-\lambda\left[E\left(\tilde{R}^{*}\right)-E\left(\tilde{R}_{\beta_{0}}\right)\right]=0
\end{gathered}
$$

Finally, dividing (25) by (26) results in

$$
\begin{gathered}
\frac{V x^{*}-\gamma}{x^{*} V x^{*}-x^{*_{1}} \gamma}=\frac{\mu-E\left(\tilde{R}_{\beta_{0}}\right) \boldsymbol{e}}{E\left(\tilde{R}^{*}\right)-E\left(\tilde{R}_{\beta_{0}}\right)} \\
\frac{\operatorname{Cov}\left(\tilde{R}_{i}, \tilde{R}^{*}-\tilde{R}_{L}\right)}{\operatorname{Cov}\left(\tilde{R}^{*}, \tilde{R}^{*}-\tilde{R}_{L}\right)}=\frac{E\left(\tilde{R}_{i}\right)-E\left(\tilde{R}_{\beta_{0}}\right)}{E\left(\tilde{R}^{*}\right)-E\left(\tilde{R}_{\beta_{0}}\right)} \quad, i=1, \ldots, n
\end{gathered}
$$




\section{Remark}

If in addition to the risky assets $i \in\{1, \ldots, n\}$ there exists a riskless asset with a deterministic return $r$, condition (21) changes to

$$
E\left(\tilde{R}_{i}\right)-r=\frac{\operatorname{Cov}\left(\tilde{R}_{i}, \tilde{R}^{*}-\tilde{R}_{L}\right)}{\operatorname{Cov}\left(\tilde{R}^{*}, \tilde{R}^{*}-\tilde{R}_{L}\right)}\left[E\left(\tilde{R}^{*}\right)-r\right], \quad i=1, \ldots, n
$$

This can be proved along the lines of SolNiK (1978), pp. 914-919.

\subsection{Efficiency of the Market Portfolio}

Now assume that the market consists of $H$ investors $h=1, \ldots, H$ with initial wealth $W_{h}$. The investors agree on the first and second moments of returns on assets

$i \stackrel{h}{\in} I$, but the growth rates of their liabilities $\tilde{R}_{L, h}, h=1$ may differ. Furthermore, each investor $h=1, \ldots, H$ solves an optimization problem of the type

$$
\min _{x \in \mathbf{R}^{n}} \operatorname{Var}\left[\tilde{R}_{A}(x)-\tilde{R}_{L, h}\right]
$$

subject to

$$
\begin{aligned}
& E\left[\tilde{R}_{A}(\boldsymbol{x})-\tilde{R}_{L, h}\right] \geq r_{s, h} \\
& \sum_{i \in I} x_{i}=1 .
\end{aligned}
$$

Then, using the results of section 3.1 one can show that the market portfolio $\boldsymbol{x}^{M}$ is efficient for an appropriately defined representative investor. The growth rate of the liabilities for the representative investor is given by

$$
\tilde{R}_{L}{ }^{M}=\frac{\sum_{h=1}^{H} W_{h} \tilde{R}_{L, h}}{\sum_{h=1}^{H} W_{h}}
$$

Applying the results of section 5.1 on the market portfolio $x^{M}$ one obtains for $\tilde{R}^{M}=\tilde{R}_{A}\left(\boldsymbol{x}^{M}\right)$

$$
E\left(\tilde{R}_{i}\right)-E\left(\tilde{R}_{\beta_{0}}\right)=\frac{\operatorname{Cov}\left(\tilde{R}_{i}, \tilde{R}^{M}-\tilde{R}_{L}^{M}\right)}{\operatorname{Cov}\left(\tilde{R}^{M}, \tilde{R}^{M}-\tilde{R}_{L}^{M}\right)}\left[E\left(\tilde{R}^{M}\right)-E\left(\tilde{R}_{\beta_{0}}\right)\right], i=1, \ldots, n
$$


respectively

$$
E\left(\tilde{R}_{i}\right)-r=\frac{\operatorname{Cov}\left(\tilde{R}_{i}, \tilde{R}^{M}-\tilde{R}_{L}^{M}\right)}{\operatorname{Cov}\left(\tilde{R}^{M}, \tilde{R}^{M}-\tilde{R}_{L}^{M}\right)}\left[E\left(\tilde{R}^{M}\right)-r\right], i=1, \ldots, n
$$

In this sense the standard versions of the CAPM (SHARPE (1964), LinTNER (1965), BLACK (1972)) are extended (see also MAYERS (1972)). In particular, the equilibrium conditions (21'), (28') shed some light on the risk premia for assets whose return is strongly correlated with $\tilde{R}_{L}{ }^{M}$. This may be typically the case for bonds.

\section{CONClusion}

In this paper, the efficient set for the asset liability model was discussed in detail. Solnik's approach for portfolio choice under inflation was refined and applied to the liability problem. Liabilities lead to a parallel shift of the efficient set. The shift vector depends linearly on an investor's sensitivity to different factors (e.g. inflation, economic growth, etc.).

A main application of the asset liability model is the portfolio problem of institutional investors. In this context it was shown, how shortfall constraints for a pension fund can be reconciled with efficiency.

Throughout the paper, it was pointed out, that the asset liability model has a wide range of application beyond pension fund economics. Consequently, in the last section a market equilibrium version for this model was derived.

For our analysis, the funding ratio was assumed to be fixed. The determination of an optimal funding ratio is a problem for further research. Combining WILKIE's and WISE's efficiency concept with our results could shed some light on this issue.

\section{ACKNOWLEDGEMENT}

We are greatly indebted to J. A. Blanco, M. Denzler, W. F. Sharpe, B. Solnik, A. D. WilkIE, H. ZIMMERMANN and an anonymous referee for many helpful suggestions which helped to improve this article. 


\section{REFERENCES}

AdLer, M. and Dumas, B. (1983). International Portfolio choice and Corporation Finance: A Synthesis, Journal of Finance, Juni 1983, 925-984.

BlaCK, F. (1972). Capital market equilibrium with restricted borrowing, Journal of Business, 45 , 444-454.

Elton, E.J. and Gruber, M.J. (1992). Optimal investment strategies with investor liabilities, Journal of Banking and Finance, 16, 869-890.

HuANG, C. and Litzenberger, R.H. (1988). Foundations for Financial Economics. North Holland, New York, Amsterdam, London.

INGERSOLL, J.E (1987). Theory of Financial Decision Making. Rowmann \& Littlefield, New Jersey.

JAEger, St. and ZimmermanN, H. (1992). On Surplus Shortfall Constraints, mimeo. HSG, St. Gallen.

JARROW, R. (1988). Finance Theory. Prentice Hall, New Jersey.

Leibowitz, M., Kogelman, St. and Bader, L. (1992). Asset performance and surplus control, Journal of Portfolio Management, Winter 1992, 28-37.

LiNTNER, J. (1965). The valuation of risky assets and the selection of risky investments in stock portfolios and capital budgets, Review of Economics and Statistics, February 1965, 13-37.

Markowitz, H. (1952). Portfolio Selection, Journal of Finance, 7,77-91.

Markowitz, H. (1987). Mean-Variance Analysis in Portfolio Choice and Capital Markets. Basil Blackwell, Oxford.

MAYERS, D. (1972). Non-Marketable Assets and Capital Market Equilibrium under Uncertainty, in Jensen, M. C., ed., Studies in the theory of capital markets. Praeger Publishers, New York.

Merton, R.C. (1973). An Intertemporal Capital Asset Pricing Model. Econometrica, September 1973, 867-887.

Merton, R.C. (1992). Continuous-time finance. Blackwell Publishers, Cambridge, Massachusetts.

SHARPE, W.F., (1964). Capital asset prices: a theory of market equilibrium under conditions of risk, Journal of Finance, September 1964, 425-442.

Sharpe, W.F. and TinT, L.G. (1990). Liabilities - A new approach, Journal of Portfolio Management, Winter 1990, 5-10.

Solnik, B.H. (1978). Inflation and optimal portfolio choices, Journal of Financial and Quantitative Analysis, December 1978, 903-925.

SVENSSON, L.E.O. and WERNER, I.M (1993). Nontraded assets in incomplete markets: Pricing and portfolio choice. European Economic Review, 37, 1993, 1149-1168.

WILKIE, A.D. (1985). Portfolio selection in the presence of fixed liabilities: a comment on "The matching of assets to liabilities", The Journal of the Institute of Actuaries, The Alden Press, Oxford, Vol.112, Part 2, No.451, September 1985, 229-277.

WiSE, A.J. (1984a). A theoretical analysis of the matching of assets to liabilities. Journal of the Institute of Actuaries, 111, part II, 375-402.

WISE, A.J. (1984b). The matching of assets to liabilities. Journal of the Institute of Actuaries, 111 , part III, 445-501.

WISE, A.J. (1987a). Matching and portfolio selection: Part 1. Journal of the Institute of Actuaries, 114 , part I, 113-133.

WISE, A.J. (1987b). Matching and portfolio selection: Part 2. Journal of the Institute of Actuaries, 114, part III, 551-568.

WISE, A.J. (1989). Matching. Journal of the Institute of Actuaries, 116, part III, 529-535.

\section{Adress of the authors}

Alex Keel, Heinz H. Müller

Fachbereich für Mathematik und Statistik

Universität St.Gallen

Bodanstrasse 4

CH-9000 St.Gallen, Switzerland. 